\title{
Electromagnetic Energy Harvesting Circuit with Feedforward and Feedback DC-DC PWM Boost Converter for Vibration Power Generator System
}

\author{
Xinping $\mathrm{Cao}^{1}$, Wen-Ren Chiang ${ }^{2}$, Ya-Chin $\mathrm{King}^{2}$ and Yi-Kuen Lee ${ }^{1}$ \\ ${ }^{1}$ Department of Mechanical Engineering, Hong Kong University of Science and Technology \\ Clear Water Bay, Kowloon, Hong Kong \\ ${ }^{2}$ Department of Electrical Engineering, National Tsing Hua University \\ Taiwan, ROC
}

Abstract - This paper presents an integrated vibration power generator system. The system consists of a mini electromagnetic vibration power generator and a highly efficient energy harvesting circuit implemented on a minute PCB and a $0.35 \mu \mathrm{m}$ CMOS integrated chip. By introducing a feedback control into the DC-DC PWM Boost Converter with feedforward control, the energy harvesting circuit can adjust the duty ratio of the converter following the variation of the input voltage and the voltage of energy storage element to get high energy conversion efficiency. The energy harvesting circuit rectifies the input AC voltage, step up the DC output of the rectifier by the DC-DC PWM Boost Converter with feedforward and feedback control and store the electric energy into a super capacitor, which can be used as a small electrical power supply for an intelligent micro sensor network.

Index Terms - DC-DC PWM boost converter, energy harvesting, integrated power generator, micro sensor network, vibration.

X. Cao, et al., "Electromagnetic Energy Harvesting Circuit With Feedforward and Feedback DC-DC PWM Boost Converter for Vibration Power Generator System," IEEE Transactions on Power Electronics, Vol. 22, No. 2, pp. 679-685, 2007. 


\section{INTRODUCTION}

Vibration powered electronic devices have been applied in several commercial products, such as Seiko Kinetic wristwatch [1], smart tennis racquet [2] and smart sports shoes [3]. In recent years, the rapid development of micro sensors for various applications [4], including remote environmental monitoring, homeland security, automotive sensors and biomedical sensors, require a miniaturized integrated distributed power supply to reduce potential problems, such as complicated interconnection, electronic noise and power control system complexity. In many of these micro sensors, power supplies from chemical energy sources are undesirable due to limited shelf life and replacement accessibility [5]-[7]. To solve this power supply problem, the conversion of electrical energy from a vibrating source to a renewable storage device $[8,9]$, such as rechargeable batteries or super capacitors [10], has been shown to be a potential and promising alternative solution $[11,12]$. The electrical energy stored in the storage device can be readily used for low-power ICs or integrated distributed micro sensors [13].

Since it is quite easy to keep a strong magnetic field with a permanent magnet, electromagnetic vibration-power generators are preferred in many applications. Some pioneering studies on mini electromagnetic vibration-power generators were performed by researchers at the University of Sheffield [5] and MIT [13]. Their work indicated that a simple spring mass system can generate power at the level of $1 \mu \mathrm{W}$. Researchers at Southampton University fabricated a vibration-based electromechanical power generator with a power generation of more than $1 \mathrm{~mW}[6]$. Another generator designed and fabricated by the same research group has been shown to produce a peak power of $157 \mu \mathrm{W}$ when the power generator was tested on an engine block [14]. Ching et al. [15] reported a millimeter-sized multi-modal vibration power generator using laser micromachining which can generated a maximum power of $830 \mu \mathrm{W}$. Boland et al. [16] presented a micromachined rotational electret power generator with a output power greater than $25 \mu \mathrm{W}$ at the rotation speed of $4170 \mathrm{rpm}$. Goto et al. [17] reported an automatic power-generating system (AGS), modified from a Seiko Kinetic quartz watch, for implantable cardiac pacemakers. This AGS system which can generate

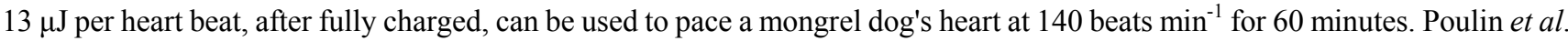
[18] presented the design and numerical analysis of an electromagnetic and a piezoelectric energy-harvesting system, for portable electronic devices, which can generate electric powers of $0.21 \mathrm{~mW}$ and $5.6 \times 10^{-3} \mathrm{~mW}$, respectively. Jeon et al. [19] developed a MEMS power generator, which consists of a $170 \mu \mathrm{m} \times 260 \mu \mathrm{m}$ lead zirconate titanate (PZT) beam, with the output power of $1 \mu \mathrm{W}$. Comparison of these vibration power generators is summarized in Table 1 .

This paper reports design, fabrication and characterization of a new mini integrated power generator system, with the maximum output power level of $35 \mathrm{~mW}$, which consists of a mini electromagnetic power generator, an interface electronic circuit and an energy storage device. The interface circuit introduces a feedback control into a feedforward DC-DC PWM Boost 
Converter as an energy harvesting circuit and shows high energy conversion efficiency. This circuit was first implemented on a mini Printed Circuit Board (PCB) and then on a $0.35 \mu \mathrm{m}$ CMOS IC chip (TSMC 2P4M CMOS technology) and can be used for the intelligent sensor networks [20].

\section{THE MINI ELECTROMAGNETIC POWER GENERATOR}

A mini electromagnetic power generator consists of a copper coil, a permanent magnet (also acting as a mass) and a spring. The permanent magnet is attached to the coil through the spring. The system works in such a manner that when there is a vibration input, the coil cuts through the magnetic flux formed by the permanent magnet due to the relative displacement between the permanent magnet and the coil. A sinusoidal electromotive force in the coil can be generated and thus transfers mechanical energy into electrical energy. Since the output power of the power generator is quite small, an energy harvesting interface circuit with high power transfer efficiency needs to be developed to recharge and store the electrical power into the energy storage elements. Furthermore, since the voltage of the renewable power supply must be high enough, the voltage should be increased to an acceptable level.

A mini electromagnetic power generator was fabricated at the Hong Kong University of Science and Technology as shown in Fig. 1, which is designed to generate power from the vibration of an automobile and other vehicles. There is a screw at the bottom of the power generator and a screw nut at the top of the mini-shaker. Therefore, the power generator firmly fixed on the shaker can have controlled vertical vibration as shown in Fig. 2. The maximum power that this device can generate is given by [5]:

$$
\begin{gathered}
P_{\max }=m \zeta_{t} \omega_{n}{ }^{3} Z_{\max }{ }^{2} \\
\zeta_{t}=\frac{c}{2 m \omega_{n}}
\end{gathered}
$$

where $m$ is the mass of the permanent magnet, $\zeta_{t}$ is the damping ratio; $c$ is the damping coefficient; $\omega_{n}$ is the resonant frequency of the vibration power generator. $Z_{\max }$ is the maximum relative displacement between the coil and the permanent magnet. Here the resonant frequency of the designed power generator is $40 \mathrm{~Hz}$. The amplitude of the oscillation produced by the mini-shaker is $3 \mathrm{~mm}$.

\section{DESIGN OF ENERGY HARVESTING CIRCUIT}

Since an electromagnetic power device generates an AC voltage while a power storage element usually requires a DC voltage input, an energy harvesting circuit needs an AC-DC rectifier connected to the two ends of the coil of the power generator in the 
first stage. If the output voltage of the rectifier is greater than that of the energy storage element, the electrical power can be directly harvested.

\section{A. Boost converter}

In many cases, the output voltage of the rectifier is smaller than that of the storage element. Therefore, it must be stepped up to be harvested into the energy storage element. In this case, a switching-mode boost DC-DC converter, as shown in Fig. 3, is used to step up the output voltage of the rectifier. In general, the ideal switch, diode and inductor should be replaced with components in series with corresponding parasitic resistors.

For a typical boost converter [21,22], the voltage gain $M$ between the input and output voltage can be expressed by the following equation if the parasitic $R_{c}$ of the capacitor is negligible:

$$
\begin{gathered}
M=\frac{V_{o}}{V_{g}}=\frac{1}{D^{\prime}+D \frac{V_{R s}}{V_{o}}+D^{\prime} \frac{V_{R L}}{V_{o}}+\frac{V_{R D}}{V_{o}}} \\
D^{\prime}=1-D
\end{gathered}
$$

where the duty ratio $D$ is defined as the ratio of the 'on' cycle time $t_{o n}$ to the whole period $T, D=t_{\text {on }} / T$. By invoking the volt-second balance principle, the conversion efficiency can be written as

$$
\eta=\frac{1}{1+\frac{R_{D}}{D^{\prime} R}+\frac{D R_{s}+R_{L}}{D^{\prime 2} R}}
$$

where $D^{\prime}=1-D$ and $R, R_{D}, R_{L}, R_{s}$ are the parasitic series resistors shown in Fig. 3.

Therefore, the efficiency is obtained and shown as a function of duty ratio for different load resistances in Fig. 4.

\section{B. Feedforward control of DC-DC PWM Boost Converter}

For a certain power output level of the power generator, energy harvesting circuit should converter the electrical energy and recharge it into energy storage element effectively. Using a constant-duty ratio, the output voltage of the DC-DC boost converter is directly proportional to the DC input voltages. Since typical vibration input during normal operation is random, the rectifier has a wide range of output voltage. Based on Equation 4, it should be possible to achieve higher energy conversion efficiency than the DC-DC converter with a constant-duty ratio in such case. The feedforward control of DC-DC PWM Boost Converter (Fig. 5) is simple and can significantly improve the performance of this DC-DC power conversion [11]. The principle of operation can be explained by the waveforms of $v_{t}, V_{R E F}$ and $v_{G S}$ shown in Fig. 6 . When the reference voltage $V_{R E F}$ at the noninverting input is higher than the sawtooth voltage, the gate to source voltage $\mathrm{v}_{\mathrm{GS}}$ goes low, otherwise, the voltage $\mathrm{v}_{\mathrm{GS}}$ goes high. Therefore, the complement of the on-duty cycle is proportional to the DC converter input voltage. 
For the feedforward control of DC-DC PWM Boost Converter, the relationship between the rated output voltage, $V_{o}$, and the sawtooth voltage is

$$
V_{O}=\left(R_{1} / R_{2}+1\right) V_{s 0}
$$

where $V_{s 0}$ is the peak value of the sawtooth voltage.

\section{Feedfoward and feedback control of DC-DC PWM Boost Converter}

Since the voltage of the energy storage element can often vary, the output voltage of the ideal DC-DC converter should be adjusted accordingly. Therefore, a feedback control circuit is introduced into the feedforward control of DC-DC PWM Boost Converter circuit as illustrated in Fig. 7. In this new circuit, the sawtooth voltage $V_{s}$ is

$$
V_{s}(t)=V_{e s} \frac{R_{4}}{R_{3}+R_{4}}\left(1-e^{-\left(R+R_{3} R_{4} /\left(R_{3}+R_{4}\right)\right)^{-1} C_{1}^{-1} t}\right)
$$

where $V_{e s}$ is the voltage of the energy storage element.

For the case of $R>>R_{3}, R>>R_{4}$, the sawtooth voltage can be written as follows:

$$
V_{s}(t) \approx V_{e s} \frac{R_{4}}{R_{3}+R_{4}}\left(1-e^{-t / R C_{1}}\right)
$$

Considering the switching period $t<<R C$, the sawtooth voltage can be approximated by a simple expression:

$$
V_{s}(t) \approx V_{e s} \frac{R_{4}}{R_{3}+R_{4}}\left(\frac{t}{R C_{1}}\right)
$$

When the switch M1 is on, the sawtooth voltage reaches its peak value and $t$ can be expressed as follows:

$$
t_{s w}=\left(1-D_{p}\right) T
$$

where $D_{p}$ is the on-duty cycle of $\mathrm{M}$ and $T$ is the period of the duty cycle of PWM boost converter.

The sawtooth peak value is directly proportional to the voltage of the energy storage element.

$$
V_{s 0} \approx V_{e s} \frac{R_{4}}{R_{3}+R_{4}} \frac{\left(1-D_{p}\right) T}{R_{1} C}
$$

In Fig. 7, M turns on when $V_{s} \geq V_{R E F}$, thus the time $t_{\text {off }}$ can be determine as

$$
t_{\text {off }}=\frac{V_{R E F}}{V_{e s}} \frac{\left(R_{3}+R_{4}\right)}{R_{4}} \frac{R_{1} C}{\left(1-D_{p}\right) T}
$$

here, $\mathrm{t}_{\mathrm{off}}$ is the time when the switch $\mathrm{M}$ is off.

$$
t_{\text {off }}=(1-D) T
$$




$$
(1-D) T=\frac{V_{1}}{V_{e s}} \frac{R_{2}}{\left(R_{1}+R_{2}\right)} \frac{\left(R_{3}+R_{4}\right)}{R_{4}} \frac{R_{1} C}{\left(1-D_{p}\right) T}
$$

The principle of operation of the feedforward and feedback control of DC-DC PWWM boost converter can be explained by the waveforms of $v_{t}, V_{R E F}$ and $v_{G S}$ shown in Fig. 8. Compared with the Feedforward control of a DC-DC PWM boost converter, the peak value of the sawtooth voltage, $V_{s 0}$, of the circuit with feedback control increases in direct ratio with the voltage of the energy storage element. The DC-DC PWM Boost Converter with feedforward and feedback control was first implemented using discrete components on a mini PCB board and tested to verify the proof of our design concept. The results are measured and show that duty ratio increase with the voltage of the energy storage element (Fig. 9). From Eqn. (3), the smaller the duty ratio $D_{p}$, the higher the conversion efficiency. That means the circuit can adjust the energy conversion efficiency with the variation of the voltage of the energy storage element. This adjustability is better for comparatively large input voltage since the duty ratio shows a stronger dependence on the voltage of the energy storage element for a large input voltage. Based on the Equation (13), the behaviors of the function represented on Fig. 9 can find its theoretical explanation.

\section{Energy harvesting circuit with Feedfoward and feedback control of DC-DC PWM Boost Converter}

Fig. 10 shows the energy harvesting circuits with the feedforward and feedback control of DC-DC PWWM boost converter. In this design, when the DC output voltage of the rectifier is greater than that of the energy storage element, the diode D6 will be conducted and the electric energy can be recharged into the energy storage element (super capacitor) directly. In other cases, the output voltage of the rectifier will be increased by the DC-DC PWM boost converter with the feedforward and feedback control and get the energy storage element recharged.

Using Eq. (13), it comes

$$
(1-D)=D^{\prime}=\frac{V_{1}}{V_{e s}} \frac{R_{2}}{\left(R_{1}+R_{2}\right)} \frac{\left(R_{3}+R_{4}\right)}{R_{4}} \frac{R_{1} C}{\left(1-D_{p}\right) T^{2}}
$$

So, the duty is,

$$
D=1-\frac{V_{1}}{V_{e s}} \frac{R_{2}}{\left(R_{1}+R_{2}\right)} \frac{\left(R_{3}+R_{4}\right)}{R_{4}} \frac{R_{1} C}{\left(1-D_{p}\right) T^{2}}
$$

For the case tht the power loss of the rectifier is negligible, the maximum power harvested by the system can be derived from Eqs.

(1) and (4) as follows:

$$
\begin{aligned}
P_{\text {tatal }} & =m \eta \zeta_{t} \omega_{n}{ }^{3} Z_{\max }{ }^{2} \\
& =\frac{m \zeta_{t} \omega_{n}{ }^{3} Z_{\max }{ }^{2}}{1+\frac{R_{D}}{D^{\prime} R}+\frac{D R_{s}+R_{L}}{D^{\prime 2} R}}
\end{aligned}
$$


The measured AC output voltage of the power generator as a function of the driving frequency of the mini shaker is shown in Fig 11. After verifying the proof of our design concept using discrete components as shown in Fig 12, an integrated energy harvesting with the same schematic structures as on the PCB board circuit was designed and fabricated using TSMC $0.35 \mu \mathrm{m}$ 2P4M CMOS technology via the CIC foundry service (National Chip Implementation Center, Hsinchu, Taiwan).

The integrated circuit designed has 752 MOS transistors totally. The layout of the core circuits is shown in Fig. 13, it consists of an AC-DC rectifier, a 555-timer circuit as a duty cycle generator, a step-up DC-DC converter and feedforward and feedback control circuit. The 555-timer circuit is designed to produce desired duty cycle. Modified by the feedforward and feedback control circuit, the duty cycle is used to turn on/off the switches of the step-up DC-DC converter. The converter steps up the output DC voltage of the rectifier. The final output energy is stored into an energy storage element off-chip.

\section{CHARACTERIZATION OF THE MINI VIBRATION POWER GENERATOR SYSTEM}

The open-circuit coil voltage ( $\left.V_{\text {coil }}\right)$ of the fabricated power generator as a function of vibration frequency was measured using a Dynamic Signal Analyzer (\#35665A, Hewlett Packard Co., USA) and a mini electromagnetic shaker (\#1640268, Brüel \& Kjær, Nærum, Denmark). Fig. 14 shows the sawtooth-wave voltage and duty-cycle voltage measured by an oscilloscope. The energy harvesting circuit has been shown to convert the vibration energy from the shaker to electrical energy and then to supply enough power for a micro sensor network consisting of 4 commercial micro accelerometers (ADXL322, Analog Devices Inc, Norwood, MA, USA).

The required power for one ADXL chip ranges from $1.2 \mathrm{~mW}$ (at $2.4 \mathrm{~V}$ supply voltage) to $3 \mathrm{~mW}$ (at $6 \mathrm{~V}$ ) according to the specification of the device datasheet. When the shaker was vibrating at the resonant frequency of the power generator, the maximum output power level of $35 \mathrm{~mW}$ and the power density of $0.41 \mathrm{~mW} / \mathrm{cm}^{3}$ was achieved. The volumes of the two energy harvesting devices and the specific power (output power/volume) of the energy harvesting devices, (IC chip based $=0.13$ $\mathrm{mW} / \mathrm{cm}^{3} \&$ PCB based systems $=0.41 \mathrm{~mW} / \mathrm{cm}^{3}$ ) which is harvested into a super capacitor, are calculated. Furthermore, the volumes of the devices are found, which are made by other researchers mentioned in Introduction section and the specific power are also calculated (Table 1).

Finally, an integrated energy harvesting circuit was designed with the EDA software package of Cadence ${ }^{\circledR}$ (Cadence Design Systems Inc., San Jose, CA, USA) and fabricated using the TSMC ${ }^{\circledR} 0.35 \mu \mathrm{m} 2 \mathrm{P} 4 \mathrm{M}$ CMOS foundry service. Figs. 15(a) and 15(b) show the photographs of one die without and with electronic packaging, respectively. Testing results show that the chip can boost the input voltage and store electrical energy into a big capacitor effectively. Table 2 summarizes the performance comparison of the fabricated CIC chip and the corresponding discrete circuit on a PCB board. 


\section{CONClusions}

An electromagnetic power generator with a high-performance the feedforward and feedback DC-DC PWM Boost Converter energy harvesting circuit, which was implemented on a PCB board first and then on a $0.35 \mu \mathrm{m}$ CMOS IC chip, has been designed and fabricated. By introducing a feedback control into a feedforward DC-DC PWM Boost Converter, the energy harvesting circuit shows high energy conversion efficiency. The measured dependence of the duty ratio of the feedforward and feedback DC-DC PWM boost converter on the voltage of the energy storage element confirms the high energy conversion efficiency of the circuit. Using a mini shaker as a vibration source, the maximum output power of $35 \mathrm{~mW}$ has been successfully harvested and applied to drive four commercial micro accelerometers.

\section{ACKNOWLEDGMENT}

This work is supported by the Institute of Integrated Microsystems, HKUST (contract \# I2MS01/02.EG08). The authors would like to acknowledge the TSMC CMOS foundry service from the National Chip Implementation Center, Taiwan, ROC (http://www.cic.org.tw). In addition, the authors would like to thank Michael Cheng in Analog Devices (HK) Inc. to provide free ADXL 322 micro accelerometers and Pak Kin Leung at HKUST to take the micrographs of the microchip. 


\section{REFERENCES}

[1] N. Hayakawa, "A study of the new energy system for quartzwatches (II)-The effective circuit for the system," Proc. Congrès Européen de Chronométrie, 1988, pp. 81-85.

[2] J. Yoshida, "Piezoelectric rackets add professional oomph," Electronic Engineering Times (EE Times, CMP Publications, Manhasset, NY, USA), June 10, 2002. Available:http://www.eetimes.com

[3] W. Knight, "Smart sports shoe adapts for optimal cushioning," New Scientist, May 6, 2004. Available: http://www.newscientist.com/news/news.jsp?id=ns99994969

[4] C.-Y. Chong and S. P. Kumar, "Sensor networks: evolution, opportunities, and challenges," Proceedings of the IEEE, 91, 2003, pp. $1247-1256$.

[5] C. B. Williams and R. B. Yates, "Analysis of a micro-electric generator for microsystems," Sensors and Actuators A 52 1996, pp. 8-11.

[6] M. El-hami, P. Glynne-Jones, N. M. White, M. Hill, S. Beeby, E. James, A. D. Brown and J. N. Ross, "Design and fabrication of a new vibration-based electromechanical power generator", Sensors and Actuators A 92 2001, pp. 335-342.

[7] T. Starner, "Human-powered wearable computing," IBM Systems Journal, vol 35, 1996 pp. 618-629.

[8] Geffrey K. Ottman, Heath F. Heath F. Hofmann, Archin C. Bhatt and George A. Lesieutre, "Adaptive piezoelectric energy harvesting circuit for wireless remote power supply”, IEEE Trans. Power Electron., vol. 17, pp. 669-676, September 2002.

[9] Geffrey K. Ottman, Heath F. Hofmann and George A. Lesieutre, "Optimized piezoelectric energy harvesting circuit using step-down converter in discontinuous conduction mode", IEEE Trans. Power Electron., vol. 18, pp. 696-703, March 2003

[10] M. K. Kazimierczuk and R. C. Cravens, “Application of super capacitors for voltage regulation in distributed power systems,” in: IEEE Power Electronics Specialists Conference, Baveno, Italy, June 23-27,1996, pp. 835-841.

[11] S. Meninger, J. O. Mur-Miranda, R. Amirtharajah, A. P. Chandrakasan and J. H. Lang, "Vibration-to-electric energy conversion," IEEE Transactions on VLSI, vol. 9, 2001, pp. 64-76.

[12] P. B. Koeneman, I. J. Busch-Vishniac and K. L. Wood, Feasibility of Micro Power.

[13] R. Amirtharajah and A. P. Chandrakasan, "Self-powered signal processing using vibration-based power generation," IEEE J. Solid-State Circuits, vol. 33 1998, pp. 687-695.

[14] P. Glynne-Jones, M. J. Tudor, S. P. Beeby and N. M. White, “An electromagnetic, vibration-powered generator for intelligent sensor systems," Sensors and Actuators A 110, 2004, pp. 344-349.

[15] N. N. H. Ching, H. Y. Wong, W. J. Li, P. H. W. Leong and Z. Wen, “A laser-micromachined multi-modal resonating power transducer for wireless sensing systems," Sensors and Actuators A 97, 2002, pp. 685-690.

[16] J. Boland, Y. H. Chao, Y. Suzuki and Y.C. Tai, "Micro electret power generator," in: Proceedings of The Sixteenth IEEE International Conference on Micro Electro Mechanical Systems (MEMS '03), Kyoto, Japan, Jan. 19-23, 2003, pp. 538-541.

[17] H. Goto, T. Sugiura, Y. Harada and T. Kazui, "Feasibility of using the automatic generating system for quartz watches as a leadless pacemaker power source," Medical and Biological Engineering and Computing vol. 37 1999, pp. 377-380.

[18] G. Poulin, E. Sarraute, F. Costa, "Generation of electrical energy for portable devices Comparative study of an electromagnetic and a piezoelectric system," Sensors and Actuators A 116 2005, pp. 461-471.

[19] Y. B. Joen, R. Sood, J.-H. Jeong, S.-G. Kim, “MEMS power generator with transverse mode thin film PZT,” Sensors and Actuators A 122, 2005 , pp. 16-22.

[20] M. K. Kazimierczuk and A. Massarini, "Feedforward control of DC-DC PWM boost converter," IEEE Trans on Circuits and Systems, vol. 44 1997, pp. 143-148. 
[21] M. H. Rashid, Power Electronics, Circuits, Devices and Applications, $2^{\text {nd }}$, Prentice Hall, Englewood Cliff, NJ, USA, Chapter 9, 1998.

[22] N. Mohan, T. M. Undeland, W. P. Robbins, Power Electronics : Converters, Applications, and Design, John Wiley \& Sons, Hoboken, NJ, USA, Chapter $7,2003$. 
Xinping Cao obtained a PhD degree in Microelectronics from Peking University, Beijing, China, in 2002, he obtained his MSc in microelectronics from The Changchun Institute of Optics and Fine Mechanics, Changchun, China in 1999, and the BSc degree in Physics from Xinjiang University, Xinjiang, China in 1996.

He was a Research Associate at the Hong Kong University of Science and Technology, Hong Kong in 2003. His major research interests focus on MEMS technologies and Analog Integrated Circuits. Currently, he is working for the School of Electrical and Electronic Engineering, Nanyang Technological University, Singapore.

Wen-Ren Chiang obtained his B.S. degree in Engineering and System Science from the National Tsing Hua University, Hsinchu, Taiwan, ROC in 2002.

Currently, He is a PhD student at the Institute of Electronics Engineering, National Tsing Hua University. His major research interests are the circuit design of CMOS image sensors.

Ya-Chin King received the BSc degree in electrical engineering from National Taiwan University in 1992, and the MSc degree in electrical engineering from the University of California, Berkeley, in 1994. She received her PhD degree in May of 1999, at University of California, Berkeley, on thin oxide technology and novel quasi-nonvolatile memory.

She joined the faculty of National Tsing-Hua University at Hsinchu, Taiwan in August 1999. She is currently an Associate Professor of the Electrical Engineering Department at NTHU. Her research topics include: advance gate dielectric, CMOS image sensors and non-volatile memory design.

Yi-Kuen Lee has been an assistant professor in the Department of Mechanical Engineering, Hong Kong University of Science and Technology since 2001. He received his BSc and MSc degrees at the National Taiwan University, Taipei, Taiwan, ROC in 1992 and 1995, respectively. He obtained his PhD in Mechanical Engineering with MEMS as the major subject in Prof Chih-Ming Ho’s laboratory, University of California, Los Angles in 2001.

He is an Assistant Professor in the Hong Kong University of Science and Technology. His research interests at HKUST include micro sensors and actuators, micro/nanofluidics, and bio-MEMS. 
TABLE I

SUMMERY OF THE SPECIFIC POWER AND THE VOLUME OF VARIOUS VIBRATION POWER GENERATORS REPORTED IN THE LITERATURE

\begin{tabular}{cccc}
\hline \hline Researchers & $\begin{array}{c}\text { Specific power } \\
\mathrm{mW} / \mathrm{cm}^{3}\end{array}$ & $\begin{array}{c}\text { Frequency } \\
(\mathrm{Hz})\end{array}$ & $\begin{array}{c}\text { Amplitude } \\
(\mathrm{mm})\end{array}$ \\
\hline Ref 6 & 4.2 & 320 & 0.94 \\
Ref 14 & 0.05 & 322 & 0.36 \\
Ref 15 & 0.8 & $60 \sim 110$ & 0.2 \\
Ref 18 & 0.071 & 2 & 5 \\
Ref 19 & 0.74 & 13.9 & 0.0045 \\
Our work & $0.41 \& 0.13$ & 42 & 3 \\
\hline \hline
\end{tabular}


TABLE 2

PERFORMANCE COMPARISON BETWEEN THE SYSTEMS WITH A DISCRETE INTERFACE CIRCUIT AND THE INTEGRATED INTERFACE CIRCUIT

\begin{tabular}{ccc}
\hline \hline ITEMS & CMOS IC chip & PCB based circuit \\
\hline Operating voltage $(\mathrm{V})$ & 3.3 & 3.3 \\
The frequency of duty cycle generator $(\mathrm{kHz})$ & $63-100$ & $10-1000$ \\
Die/PCB Area $\left(\mathrm{cm}^{2}\right)$ & 0.03 & 49 \\
The highest Output Voltage $(\mathrm{V})$ & 3.7 & 4.5 \\
Max Output power $(\mathrm{mW})$ & 4.0 & 35 \\
Volume of the systems $\left(\mathrm{cm}^{3}\right)$ & 31.5 & 86 \\
The specific power $\left(\mathrm{mW} / \mathrm{cm}^{3}\right)$ & 0.13 & 0.41 \\
\hline \hline
\end{tabular}




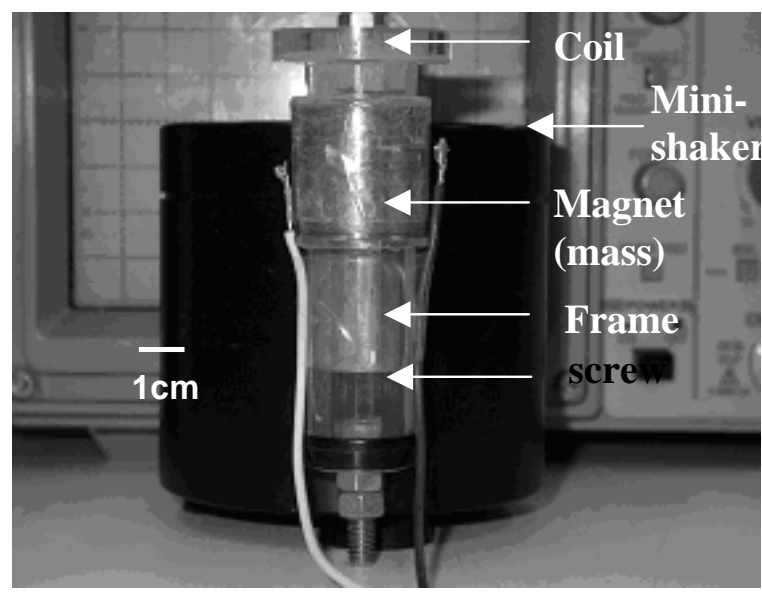

Fig. 1. Photograph of the mini vibrational power generator. 


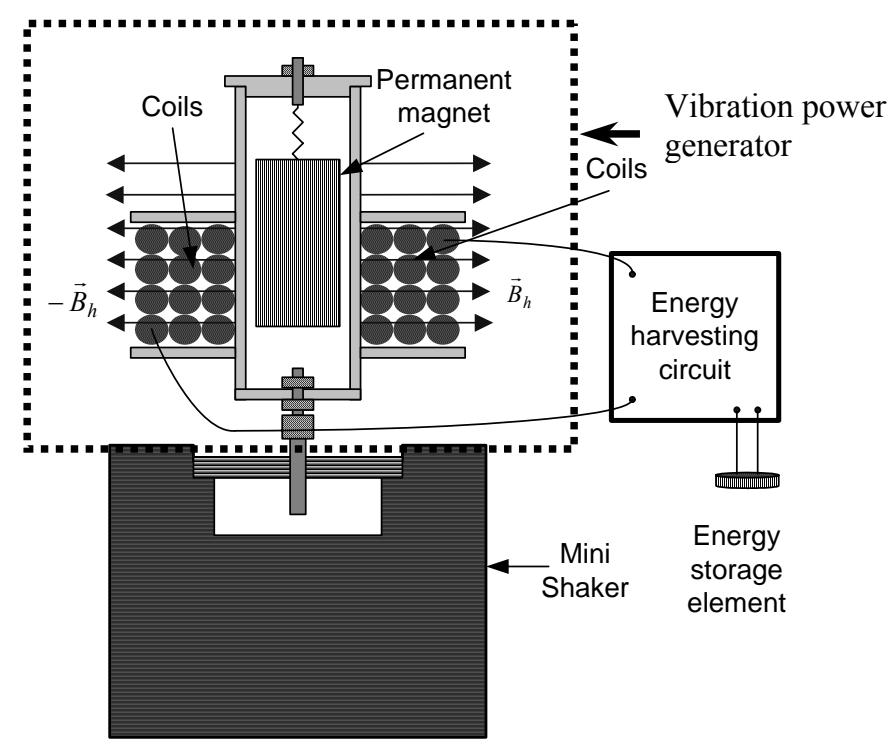

FIG. 2. THE SCHEMATIC DIAGRAM OF THE WHOLE VIBRATION POWER GENERATOR SYSTEM. 


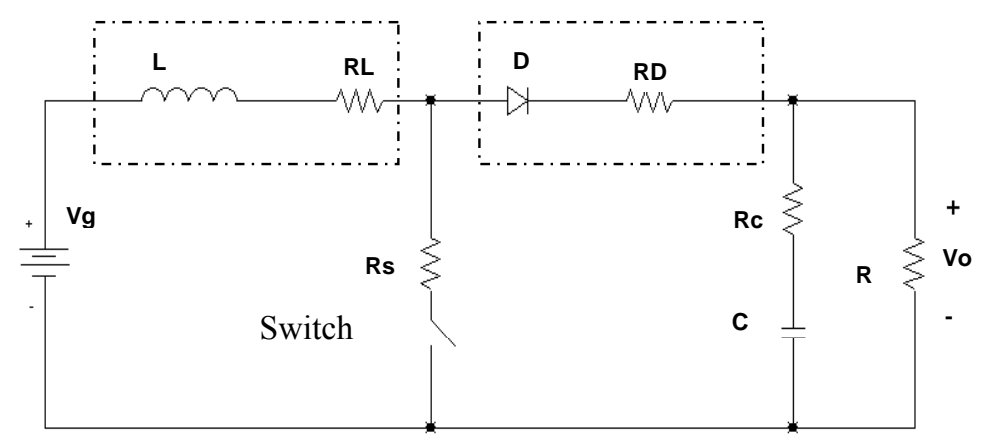

Fig. 3. Typical boost converter 


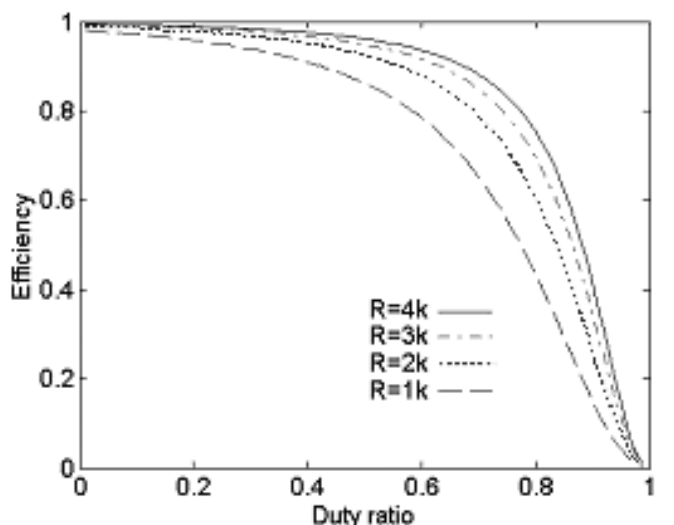

Fig. 4. Power conversion efficiency as a function of duty ratio for different load resistances for a practical boost converter. The unit for the resistance $R$ is $\mathrm{Ohm}\left(\mathrm{R}_{\mathrm{L}}=6.0 \Omega\right.$, $\mathrm{Rs}=1 \Omega$ and $\left.\mathrm{R}_{\mathrm{D}}=9 \Omega\right)$. 


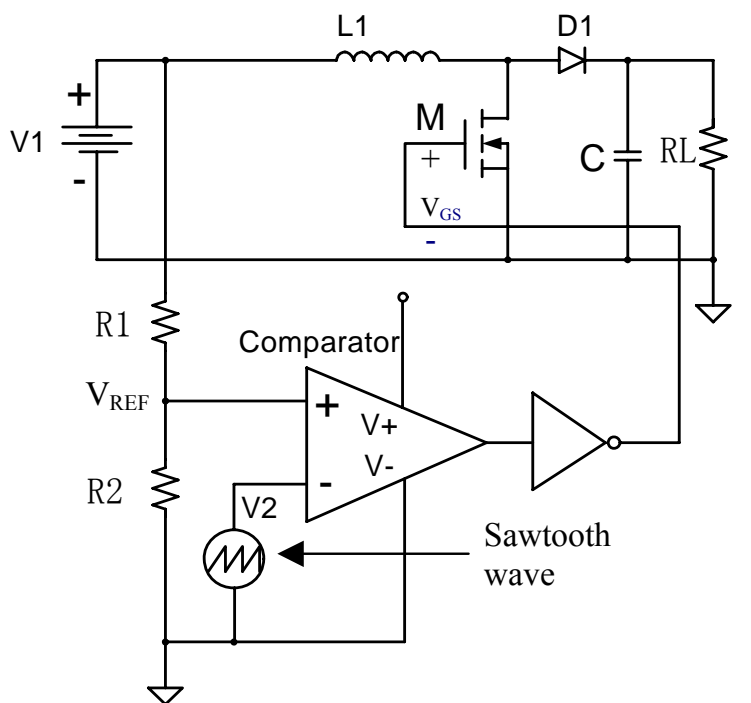

Fig. 5. Feedforward control of a DC-DC PWM boost converter. 

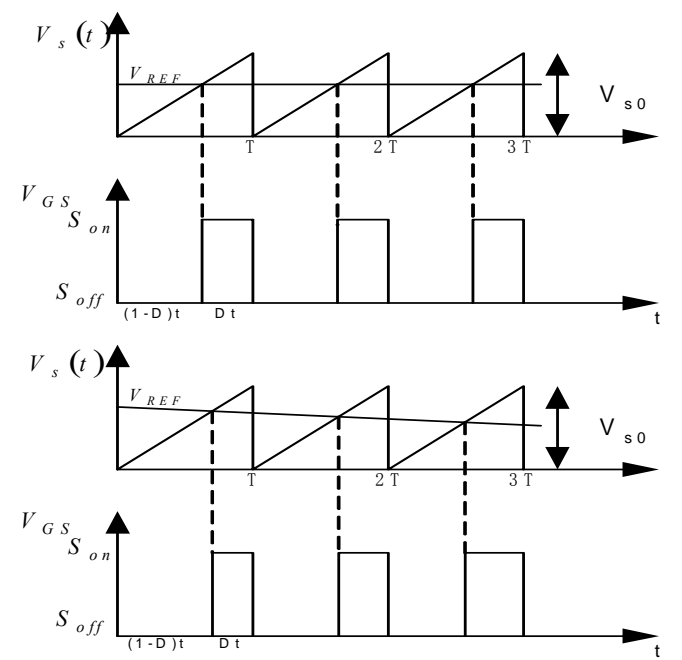

Fig. 6. Waveforms in the feedforward control circuit of Fig. 5 


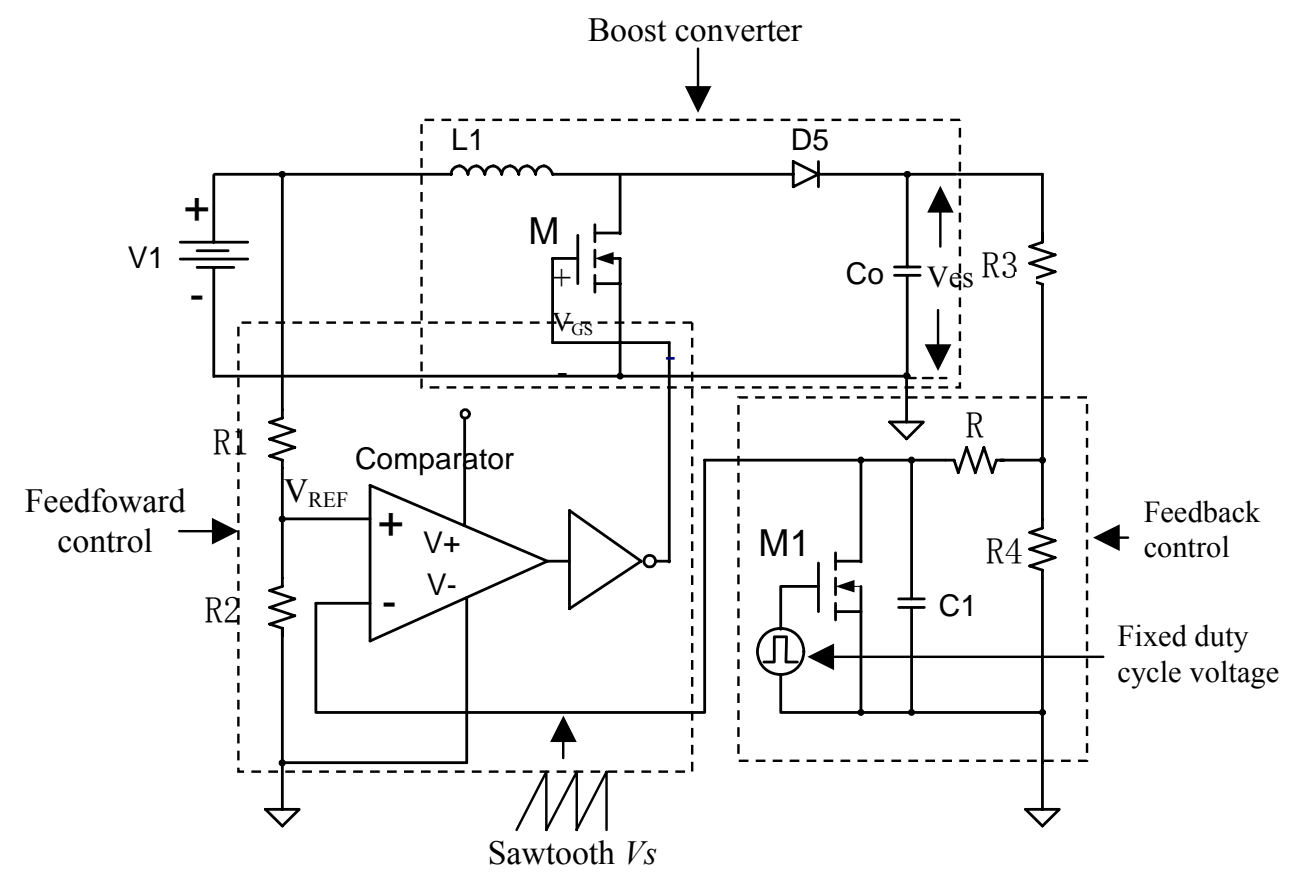

Fig. 7. Feedforward and feedback control of DC-DC PWWM boost converter. 


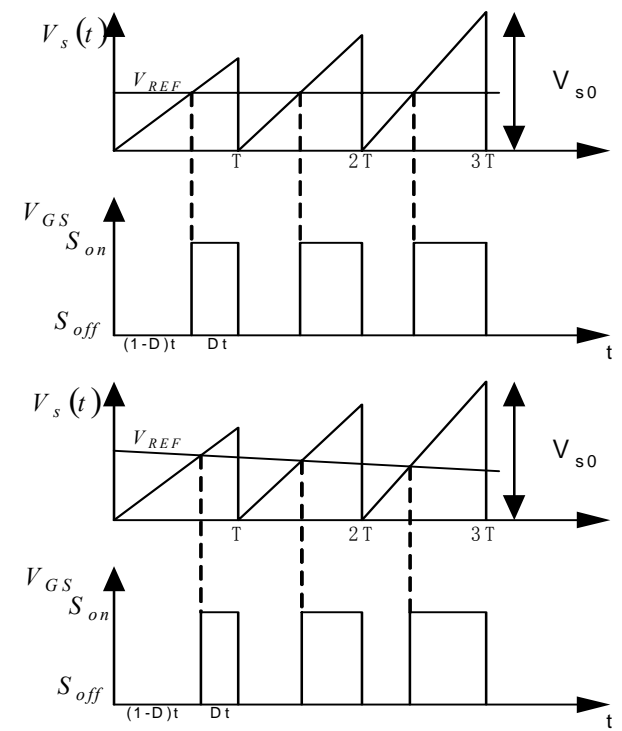

Fig. 8. Waveforms in the feedforward and feedback control circuit of Fig. 5 


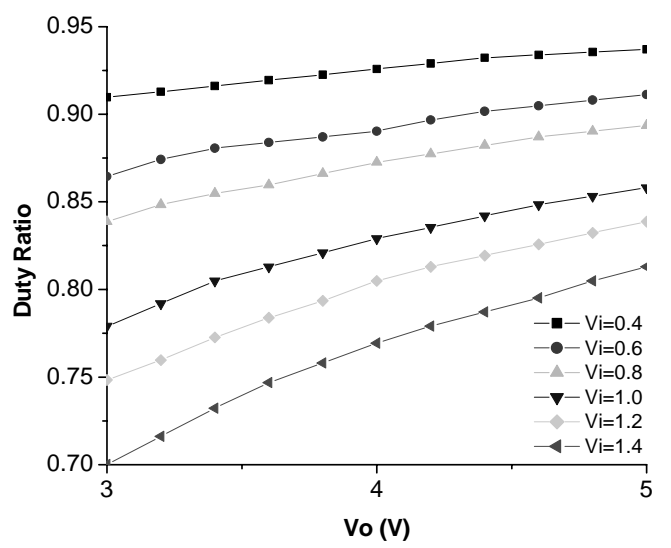

Fig. 9. Duty ratio as a function of the output voltage for different input voltages of a DC-DC PWM boost converter with feedforward and feedback control. 


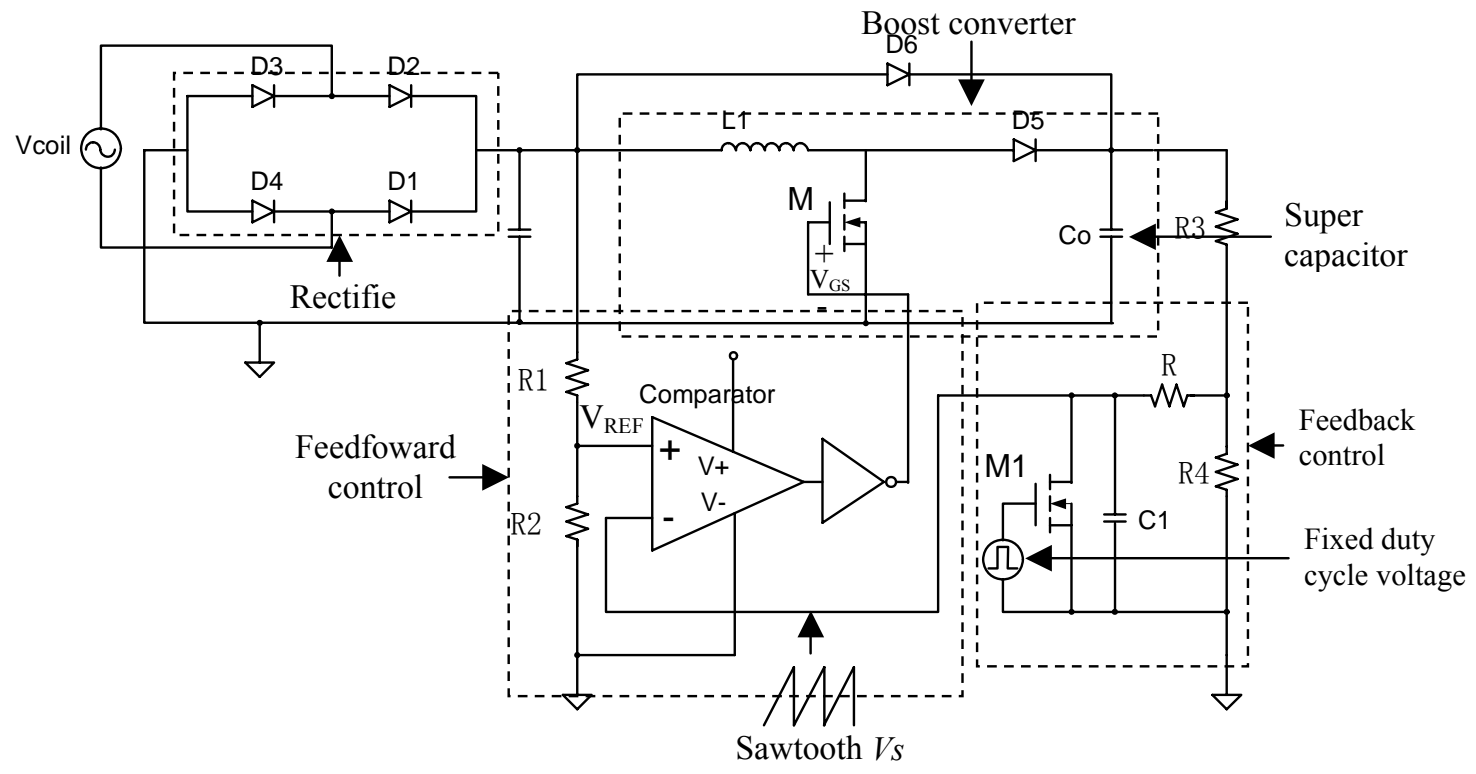

Fig. 10. Energy harvesting circuit with feedforward and feedback control of DC-DC PWWM boost converter. 


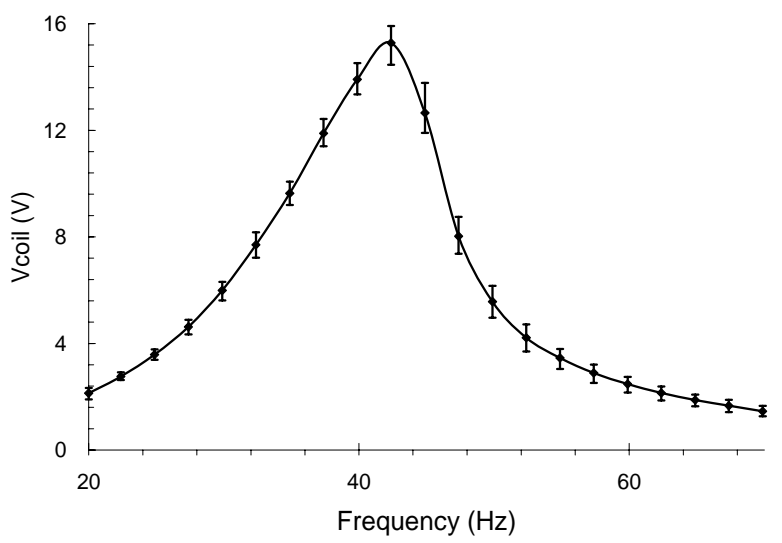

Fig. 11. Measured output voltage of the mini vibration power generator as a function of the driving frequency of the mini shaker. The amplitude of the driving motion is $3 \mathrm{~mm}$, the magnetic field strength is $1.1 \mathrm{~T}$ and the effective coil length is $1.2 \mathrm{~km}$. 


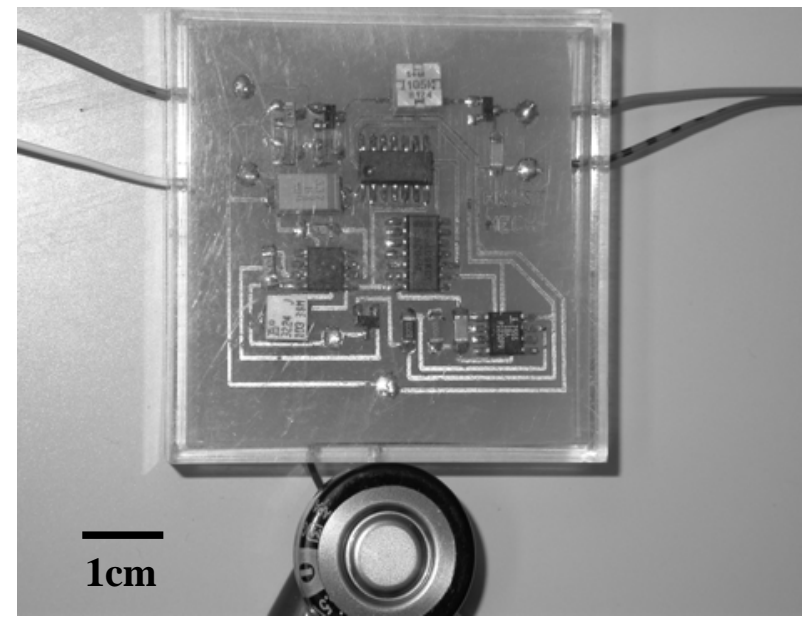

Fig. 12. Discrete circuit implementation of the energy harvesting circuit on a printed circuit board. 


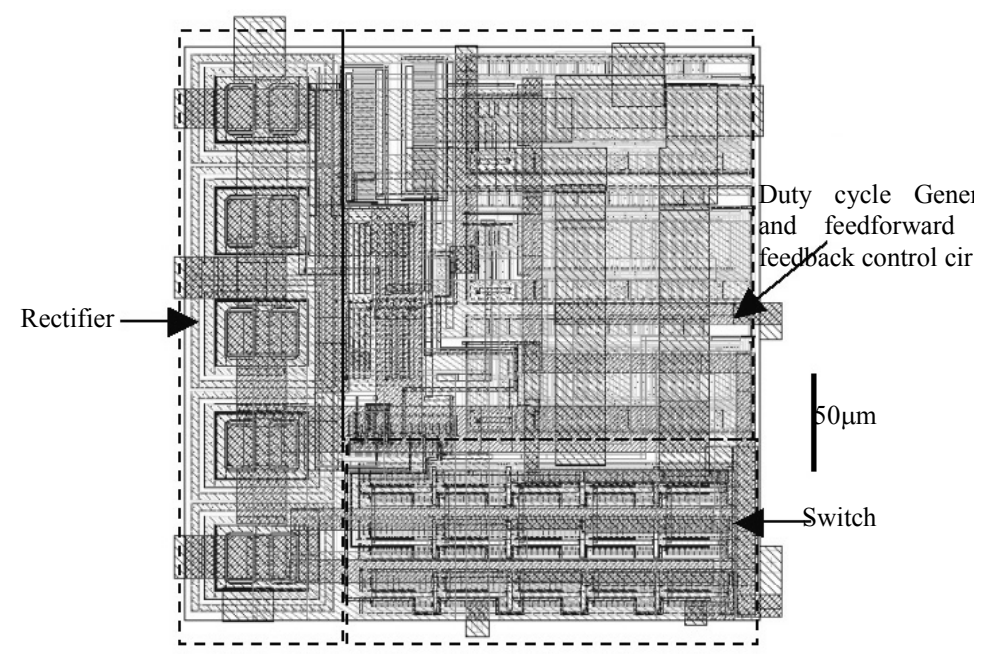

Fig. 13. Layout for the $0.35 \mu \mathrm{m}$ CMOS integrated energy harvesting circuit. 


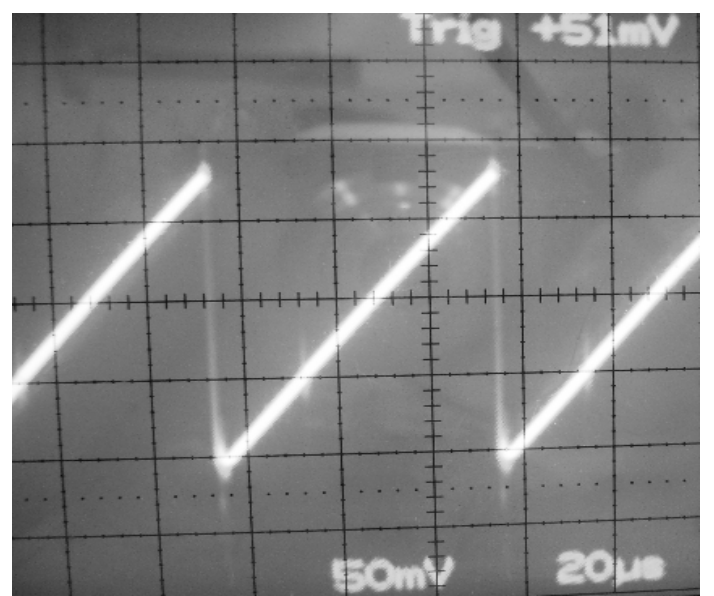

(a)

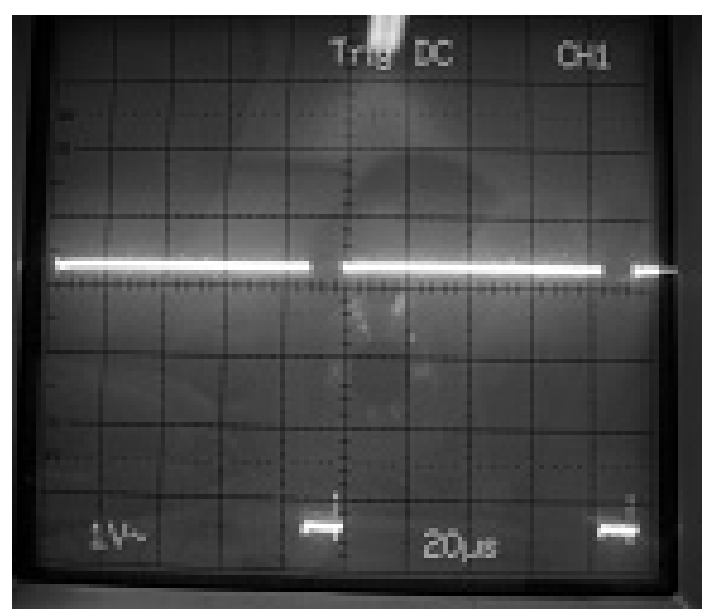

(b)

Fig. 14. Snapshots of the voltages in the energy harvesting circuit on an oscilloscope, (a) the sawtooth-wave voltage $V_{s}$, (b) the voltage of the feedback-control duty cycle. 


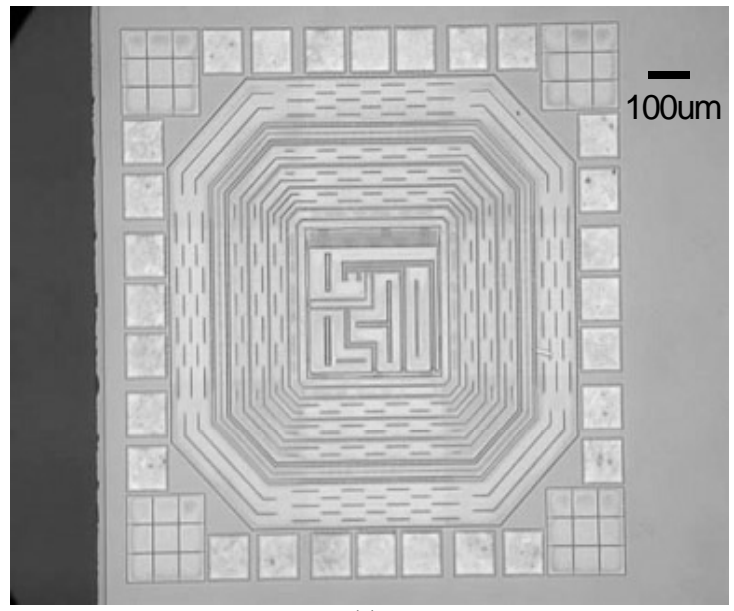

(a)

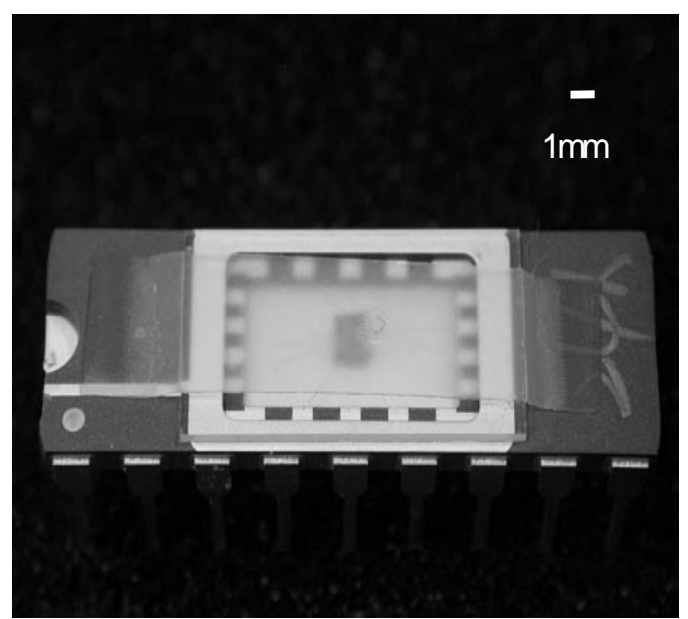

(b)

Fig. 15. Photographs of the energy-harvesting CMOS IC chip: (a) a fabricated die, (b) a DIP packaged chip. 